
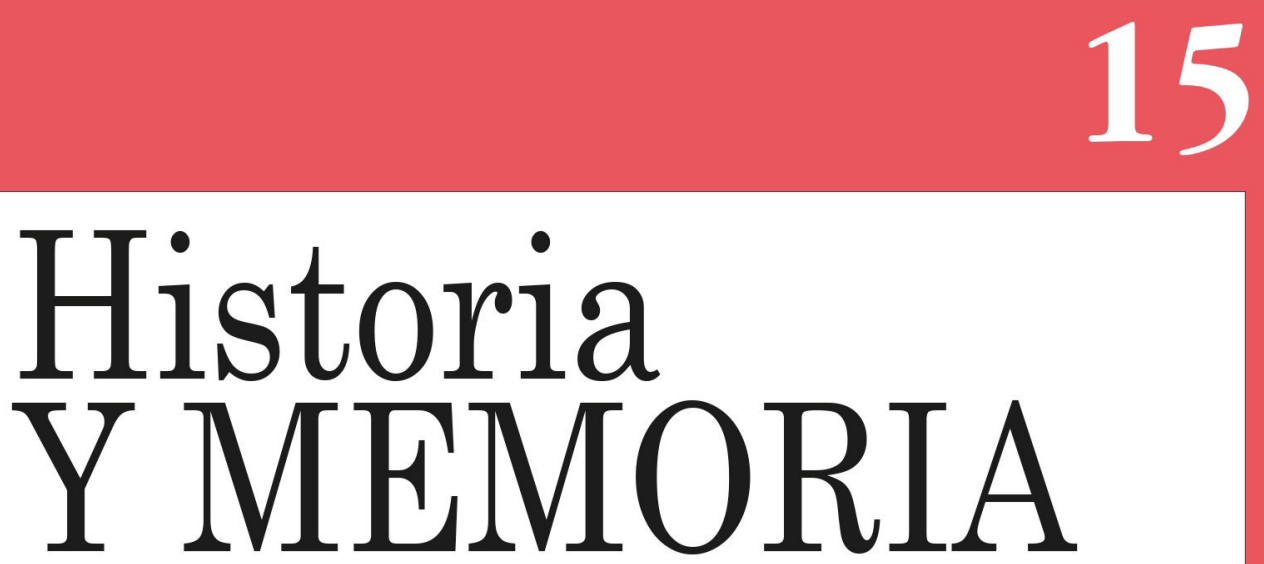

ISSN: 2027-5137 Julio - Diciembre, Año 2017 - Tunja, Colombia

La guerra fría en Colombia. Una periodización necesaria https://doi.org/10.19053/20275137.n15.2017.6119

Liborio González Cepeda orcid.org/0000-0002-0188-5985

Páginas: 295-330

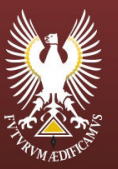




\title{
La guerra fría en Colombia. Una periodización necesaria*
}

\author{
Liborio González Cepeda ${ }^{1}$ \\ Universidad Pedagógica y Tecnológica de Colombia
}

Recepción: 13/09/2016

Evaluación: 21/02/2017

Aprobación: 31/03/2017

Artículo de Investigación e Innovación.

https://doi.org/10.19053/20275137.n15.2017.6119

\section{Resumen}

El artículo presenta una periodización del desarrolló la Guerra Fría en Colombia, el enfrentamiento entre potencias y bloques de poder que se trasladó al interior de los países e hizo del conflicto un problema de relaciones al interior de cada uno. Muestra la existencia de tres grandes periodos que si bien tienen puntos de encuentro con las periodizaciones del conflicto internacional, tiene sus particularidades que responden al devenir político del país. Siendo la guerra fría una guerra internacional de ideas que asume como escenario el interior de cada estado, su periodización se hace igualmente particular y toma como fundamento los conflictos entre las diferentes fuerzas que luchan internamente por el poder. Como confrontación por proyectos societales, el texto se ubica dentro de la historia política y se desarrolla tomando como fuentes los documentos que dan cuenta de las principales acciones, sucesos y políticas que desde los diversos actores explican el devenir histórico del país. Pero como es parte de

\footnotetext{
* Artículo derivado de la investigación «Guerra fría y discurso político en la formación del imaginario anticomunista en Colombia: 1948-1958». La investigación inició en julio de 2010 y finalizó en noviembre de 2015.

1 Doctor en Historia (UPTC). Integrante del grupo de investigación: «Conflictos sociales Siglo XX» - UPTC. Líneas de Investigación: Partidos y movimientos políticos, y Guerra Fría. Publicaciones recientes: «El multilateralismo en América: estrategia del dominó en la Guerra Fría", Criterio Jurídico Garantista 9, n 14 (2016): 68-85. \ liboriogonzalez@hotmail.com (iD orcid.org/0000-0002-0188-5985
} 
un conflicto internacional también se toman como fuentes los documentos que relatan y describen las principales acciones orientadas desde los Estados Unidos para el caso colombiano y en general para el continente.

Palabras claves: Guerra Fría, comunismo, capitalismo, bloques de poder, subversión, contención.

\section{The Cold War in Colombia. A Necessary Periodization}

\section{Summary}

This article presents a periodization of the Cold War in Colombia, the confrontation between the powers and power blocks transferred to different countries, creating a problem of relations inside each of them. The study shows the existance of three great periods, coinciding in some points with periodizations of the international conflict, but also possessing particularities that respond to the political development of the country. Based on the fact that the Cold War was an international war of ideas that assumed the interior of different nations as its scenery, its periodization must equally take into account the particularities of the different cases, and the conflicts between the different forces struggling internally for power. As a confrontation for societal projects, this study is framed in political history and its documentary sources are the different actions, events, and policies that explain the historical development of the country, from the perspectve of its different actors. Nevertheless, as part of an international conflict, it also uses documents that narrate and describe the principal actions promoted by the United States specifically for the Colombian case and in general for the whole continent.

Key words: Cold War, Communism, Capitalism, Power blocks, Subversion, Containment. 


\section{La Guerre Froide en Colombie. Une périodisation nécessaire}

\section{Résumé}

Cet article ébauche pour la Colombie une périodisation de la Guerra Froide, conflit entre puissances et bloques de pouvoir qui s'est immiscé à l'intérieur des différents pays, de telle sorte qu'il est devenu aussi un problème domestique. Le texte montre l'existence de trois grandes périodes qui ne coïncident pas toujours avec celles du conflit international et qui répondent à des particularités propres de la vie politique du pays. Il ne pouvait pas être autrement, puisque si la Guerre Froide est une guerre internationale d'idées, elle se développe à chaque fois dans la scène interne des États, en prenant compte des forces qui luttent pour la conquête du pouvoir. L'article se place dans le champ de l'histoire politique et est construit à partir de documents qui rendent compte des principales actions, événements et politiques des différents acteurs. Mais, puisque c'est en même temps un conflit international, on s'appuie également sur des documents qui décrivent les principales actions entreprises par les EtatsUnis en Colombie et, en général, dans le continent tout entier.

Mots-clés: Guerre froide, communisme, capitalisme, bloques de pouvoir, insurgés, contention.

\section{Introducción}

Uno de los sucesos más significativos en la historia de la humanidad fue la Guerra Fría, no sólo por su incidencia en la organización ideológica de los Estados, sino por lo que significó para las naciones la adopción de políticas internas orientadas, dirigidas y financiadas por los Estados Unidos, todo con el fin de evitar que los habitantes de estos países abrazaran la sola idea de darle cabida al comunismo. No obstante su trascendencia, ha sido un tema marginal en el interés de los historiadores nacionales, y sólo tangencialmente ha sido abordado por algunos cientistas sociales, más desde la 
óptica de las relaciones internacionales que desde cualquier otro ángulo.

La Guerra Fría significó un viraje total en las relaciones de poder, en la organización misma del Estado, y principalmente en los imaginarios, se hace necesario iniciar por presentar una propuesta de periodización de este conflicto para el caso particular colombiano que comprende, primero, una fase de adopción del lenguaje anticomunista o de ideologización de la sociedad (1948-1958), un segundo momento donde el comunismo se hace presente como objeto real (1958-1979), y una tercera fase de agudización del conflicto (1979-1991). Lo anterior obedece a que si bien en la historiografía universal existe una periodización que responde a las particularidades del enfrentamiento entre la Unión Soviética y los Estados Unidos, es necesario, en un ejercicio de comprensión más objetiva de la historia nacional, el estudiar cómo se presenta este fenómeno en Colombia, con sus intensidades y particularidades.

La historiografía universal ${ }^{2}$ reconoce las siguientes fases de la guerra fría: Una primera comprendida entre 1948 y 1953 caracterizada por la consolidación del bipolarismo, la crisis de Berlín de 1948, la formación de las dos repúblicas alemanas, la formación de China comunista y su inserción en el escenario internacional, el conflicto en Corea y el desarrollo del Macartismo y la caza de Brujas en Norteamérica; una segunda fase ubicada entre 1953 y 1970/75, llamada de coexistencia pacífica, que coincide con la muerte de Stalin, la llegada al poder de Kruschev y su declaración de la posibilidad de la coexistencia de los dos modelos políticos con solución pacífica de las diferencias, las expresiones de guerras localizadas en el Canal del Suez, la revuelta de Hungría en 1956, la crisis de los misiles en Cuba, la segunda crisis de Berlín, la creación del muro en 1961, y la guerra de Vietnam; y

$2 \quad$ Ronald J. Powaski, La guerra fría. Estados Unidos y la Unión Soviética, 19171991 (Barcelona: crítica, 2000); Josep Fontana, Por el Bien del Imperio. Una historia del mundo desde 1945 (Barcelona: Pasado \& Presente, 2012); Ramón Villares y Ángel Bahamonde, El Mundo Contemporáneo, Siglo XIX y XX (Madrid: Taurus, 2001); Francisco Veiga y otros, La Paz simulada. Una historia de la Guerra Fría 19411991 (Madrid: Alianza Editorial, 1997); Andre Fontaine, Historia de la Guerra Fría (Barcelona: Editorial Luis Caralt, 1970, entre otros. 
la tercera fase entre 1975 y 1990/91 o fase final con los últimos movimientos de la URSS en Afganistán, Camboya, Angola y Mozambique, el apoyo norteamericano a las dictaduras y gobiernos derechistas en América como en Chile, Argentina, Uruguay, Nicaragua, entre otros; el fortalecimiento de las guerrillas en Centroamérica y el impulso a las «contras» por parte del gobierno de los Estados Unidos, la guerra de las Galaxias impulsada por Reagan, el dominio neoconservador en EEUU y Gran Bretaña con Reagan y Margaret Tacher, la crisis y desintegración de la URSS con Gorbachov, entre los sucesos más significativos.

Teniendo los anteriores referentes de la forma más común de periodizar lo que fue la Guerra Fría, y que responde a una mirada tradicional del conflicto donde primó lo bélico o la amenaza más latente de convertirse en enfrentamiento armado entre las dos potencias, encontramos que ésta percepción de los períodos no se corresponde con las vivencias o desarrollos en el continente americano y de forma puntual con los hechos que se vivieron en Colombia. El problema de esa periodización global radica en que se asumió como criterio el de la lógica de las confrontaciones, esto es, el clima del enfrentamiento o de acciones en donde las dos superpotencias estuvieron más próximas a hacer uso de la fuerza, dejando de lado el hecho de que durante todo ese periodo de 1947 a 1991 no existió un choque militar directo que confrontara las fuerzas militares de las dos potencias, y que por el contrario, la guerra se trasladó al interior de las naciones convirtiéndose en un enfrentamiento entre habitantes del mismo país; por esta razón, la necesidad de una periodización local se ubica en el hecho de que la llamada "guerra fría» fue, en esencia, una guerra por la conquista de las mentes y las voluntades de los habitantes de las diversas naciones, primero para impedir el desarrollo de la otra concepción del mundo, y segundo, para mantener cohesionado a los países dentro del bloque. Desde esta otra lógica de la Guerra Fría, las acciones de los gobernantes, sus discursos, políticas y decisiones durante todo este periodo estuvieron enmarcados dentro de ese lenguaje de tensión y de miedo al comunismo, determinando así los niveles de confrontación interna y dándole a la historia de la 
Guerra Fría su propia dinámica que permite su periodización así: una fase de consolidación ideológica y de Unidad nacional entre 1948 y 1958; una segunda fase donde el enemigo interno se consolida a partir de la formación de guerrillas de corte comunista y se impone la necesidad de la seguridad antes que la solución a los problemas, periodo comprendido entre 1958 y 1978; y la tercera fase, la fase de la guerra abierta entre 1979 y 1990/91, donde la amenaza comunista es concebida como real por los niveles de desarrollo y control alcanzado por las organizaciones guerrilleras tanto en Colombia como en Centroamérica.

Por esta razón, el ejercicio se realiza a partir de una descripción del contexto americano y se consolida con la descripción de los principales hechos que marcaron la vida nacional y que estuvieron relacionados con el conflicto universal de la segunda mitad del siglo XX.

\section{Primera Fase: Consolidación del imaginario anticomunista: 1948-1958}

El hecho que marcó el comienzo de la Guerra Fría en Colombia, -y en América Latina, según Gonzalo Sánchez ${ }^{3}-$, lo constituyó el asesinato de Jorge Eliecer Gaitán en Bogotá el 9 de abril de 1948. Si bien desde la Segunda Guerra Mundial, Estados Unidos venía promoviendo la necesidad de crear esquemas de "defensa del hemisferio» frente a un posible "enemigo externo», los hechos del 9 de abril, en plena reunión de la IX Conferencia Panamericana, significaron para el presidente Truman y para su Secretario de Estado, George Marshall presente en la Conferencia en Bogotá, una oportuna y excelente demostración de que el comunismo soviético tenía pretensiones expansionistas en este hemisferio. Si bien, los Estados Unidos a través de su secretario de Estado habían propuesto que en la Conferencia se analizara el tema de la subversión y el comunismo en el continente ${ }^{4}$. Ésta propuesta

3 Ver Gonzalo Sánchez, ed. Grandes Potencias, el 9 de abril y la violencia. (Bogotá: Planeta, 2000).

4 Ver: Pierre Gilhodés, «El 9 de abril y su contexto internacional», en Grandes Potencias, el 9 de abril y la Violencia, ed. Gonzalo Sánchez (Bogotá: Planeta, 2000), 45-62. 
no tuvo acogida por parte de los representantes de varios países y por ende no formó parte de la agenda final acordada. Este clima internacional en donde muchos países se negaban a aceptar ciegamente las recomendaciones de los Estados Unidos cambió luego del 9 de abril con el asesinato de Gaitán. El hecho fue aprovechado inmediatamente por la potencia capitalista para confirmar y difundir la idea de que América Latina comenzaba a ser objeto del expansionismo comunista soviético. Ante estas «evidencias» las posiciones adversas de algunos países cambian y se empieza a consolidar una unidad hemisférica alrededor de las imposiciones y políticas emanadas desde el país del norte ${ }^{5}$ que garantizarían la "contención» de la amenaza roja.

Si bien, los objetivos de integración que se venían adelantando en el continente no eran homogéneos en el sentido que convocaran la voluntad de todos los gobiernos, como se mencionó anteriormente, los hechos de Bogotá si se convirtieron en su acelerador. La firma de la Ley de Seguridad Mutua de 1951 y el Pacto de Ayuda Militar -MAP- en 1952 como desarrollos del Tratado de Asistencia Recíproca de 1947, son ejemplos que reflejan la incursión de los Estados Unidos en el direccionamiento de la política colombiana. Uno de los aspectos abordados fue la destinación de recursos para fortalecer los ejércitos latinoamericanos y para la preparación de los hombres que se encargarían de dar los golpes militares y de establecer las dictaduras en buena parte del continente, en particular en aquellos países donde se insinuaban procesos revolucionarios o luchas populares como Bolivia, Cuba,

$5 \quad$ En este contexto van a aparecer unas políticas internacionales de corto, mediano y largo plazo. Dentro de los objetivos de corto plazo aparece la consolidación de la unidad hemisférica, la Pax Americana, la promoción de gobiernos aliados, la seguridad militar; mientras a mediano y largo plazo se pretende la estabilidad económica y política que garantice eliminar las condiciones que podrían dar fuerza al comunismo. Para darle salida a este punto se propone el Programa del Punto Cuatro que desarrolla la Doctrina Truman. Ver «El punto cuatro del presidente Truman», Otra clase de historia, acceso el 27 de octubre de 2013, https://search.yahoo.com/yhs/ search?hspart=adk\&hsimp=yhs-adk_sbyhp\&p=el+punto+cuatro+del+presidente+tr uman\&param $1=20170308 \&$ param $2=2 \mathrm{fb} 37 \mathrm{~d} 58$-ffda-426c-ade9- 73c0501bf4f5\&param 3=packages_5.0.1 CO appfocus5\&param $4=$ googledisplay $\sim$ Chrome $\sim$ el+punto+cuatr o+del+presidente+truman 
Guatemala, Argentina y Venezuela ${ }^{6}$. Con estas medidas se pretendió fortalecer la seguridad del continente, mientras contradictoriamente Estados Unidos se presentaba como defensor de la democracia y de las libertades.

Esta fase coincide con el momento de consolidación del bipolarismo político a nivel mundial; podría llamarse la «fase política» de la Guerra Fría que buscó arraigar la hegemonía ideológica en la medida que la pretensión de cada una de las potencias era imponerse sobre la otra y hacer de su proyecto societal el único válido. Corresponde al momento en que se pretendió hacer prevalecer la idea de "seguridad colectiva» a través de instituciones políticas, económicas, culturales y militares como el TIAR y la OEA en América, y de la estructuración de las acciones colectivas como característica de la diplomacia intercontinental. La lógica que imperó en esta coyuntura fue la de que la paz internacional era viable sólo a través de la solidaridad, es decir, por el mayor grado de cooperación que se ofrecieran recíprocamente los Estados. En esta fase, si bien hay grandes tensiones a nivel mundial, también existen permanentes acuerdos para garantizar los límites y la estructura del sistema mundial que nace de la conferencia de Yalta (febrero de 1945), en la que La Cortina de Hierro expresa ese acuerdo tácito para que la revolución socialista no avanzara hacia occidente, ni el capitalismo se implantara en el bloque soviético ${ }^{7}$. La Segunda Guerra Mundial terminaba con un el establecimiento de una frontera física e ideológica que finalmente dividió a Europa en los dos bloques y que fue confirmada por Churchill cuando en una conferencia en Estados Unidos en 1946

6 Ver: Daniel Pereyra. Del Moncada a Chiapas. (España: Libros de las cataratas, $2^{a}$ edición, 1995), 21.

7 Las conferencias internacionales que tuvieron lugar durante la Segunda Guerra Mundial fueron construyendo el escenario para el nuevo orden mundial de posguerra. Se destacan la conferencia en agosto de 1941 entre Winston Churchill, primer ministro británico, y Franklin D. Roosevelt, presidente norteamericano; la conferencia de Teherán, en noviembre de 1943; la de Yalta en 1945 y la de Potsdam en julio del mismo año. En estas últimas se fija el destino de Alemania, pero también las respectivas zonas de influencia de las dos nuevas potencias rivales, dando lugar así a la creación de los bloques de poder en que quedó divido el mundo hasta 1991. Ver: Villares y Bahamonde, El mundo contemporáneo..., 314. Powasky, La guerra fría. 
dijo: «Desde Stettin en el Báltico, a Trieste, en el Adriático, ha caído sobre el continente (Europa) un telón de acero» ${ }^{8}$. Se trató de trazar la línea hasta donde podían actuar cada una de las nuevas potencias que de aliadas iniciaban su vida de enemigas y antagónicas.

En el caso colombiano, esta es una fase de transición, en donde, a pesar de coincidir con la fase de más alta exacerbación de los odios partidistas, también se dio paso a la confluencia de los dirigentes partidistas, donde el imaginario comunista que estuvo ligado al liberalismo se va deslindando de esta corriente política para, poco a poco, irse convirtiendo en el nuevo enemigo, ahora sí el comunismo propiamente dicho.

Se puede afirmar que es la fase en la cual se propician las condiciones ideológicas que tienen que ver con la consolidación del «imaginario anticomunista y antisoviético», tanto en la dirigencia política como en las fuerzas militares, y se crean las condiciones para el intervencionismo americano en los campos político, económico y social. Es el momento en el que Estados Unidos consolidó las condiciones para influir en el rumbo de la política Colombiana y Latinoamericana; precisamente en esta fase se encuentran en desarrollo las políticas diseñadas como parte del Programa del Punto Cuatro ${ }^{9}$-como se le llamó a la política de Truman para contener al comunismo-, dentro de las cuales América fue uno de los principales objetivos.

En Colombia, además del asesinato de Gaitán, tuvo lugar en esta fase la formación de las primeras guerrillas

8 Ver: «Orígenes de la Guerra Fría. Wiston Churchil. "El telón de Hierro". 5 de marzo de 1946», Historia1imagen, acceso el 13 de noviembre de 2013, https:// historia1imagen.cl/2007/06/01/origenes-de-la-guerra-fria-wiston-churchill-el-telonde-hierro-5-de-marzo-1946/

9 Los cuatro puntos del programa de Truman fueron: (1) inquebrantable apoyo a las naciones Unidas y organismos afiliados, (2) continuación del programa para el restablecimiento de la economía mundial, (3) fortalecimiento de las naciones amantes de la libertad contra los peligros de la agresión, y (4) un audaz programa nuevo para poner a disposición del mejoramiento y desarrollo de las regiones atrasadas los beneficios de nuestros adelantos científicos y de nuestro progreso industrial. Ver: «El punto cuatro del presidente Truman...». 
tanto comunistas ${ }^{10}$ como liberales ${ }^{11}$. Precisamente Daniel Pereyra nos habla de la guerrilla organizada por Rafael Rangel en la región de San Vicente de Chucurí -Santanderllamada Fuerza de Resistencia Civil, de las guerrillas del Llano formadas por Eduardo Franco y de las que forman en el departamento de Tolima con influencia del Partido Comunista $^{12}$. Fue tan significativo el desarrollo y acogida de estas organizaciones en la población que Pereyra habla de que «para 1952 la guerrilla operaba en doce frentes regionales, sumaba entre 35.000 y 40.000 hombres armados, y constituía un peligro para el régimen, asumiendo el carácter de una verdadera revolución social» ${ }^{13}$. El Mayor Gonzalo Bermúdez considera que los niveles de desarrollo y articulación entre estas nuevas fuerzas irregulares fueron muy significativa hasta el punto en que la correlación de fuerzas ya era

10 Se trató de grupos comunistas de resistencia que durante la violencia interpartidista actuaron al lado de las guerrillas liberales creadas para hacerle frente a la policía chulavita, y a grupos conservadores o "pájaros» que actuando a nombre del gobierno afectaban el derecho a la vida y a los bienes de quienes no profesaban el mismo credo político del mandatario. Grupos armados que distaban mucho de ser revolucionarios como afirma Pecaut. Ver Daniel Pecaut. Las FARC, ¿una guerrilla sin fin o sin fines? (Bogotá: Norma, 2008), 27. Si bien la mayor parte de investigaciones subrayan 1964 como el surgimiento de las FARC como primera guerrilla comunista, es bueno recordar que tras el asesinato de Gaitán muchos dirigentes del Partido Comunista se vieron obligados a actuar en la clandestinidad y algunos acudieron a crear grupos armados a manera de autodefensas, que fueron los gérmenes de las guerrillas comunistas, aunque, para entonces, sin claridad sobre sus fines estratégicos, como afirma Mario Aguilera. Ver: Mario Aguilera Peña, Las FARC: la guerrilla campesina 1949-2010. ¿Ideas circulares de un mundo cambiante? (Colombia: Corporación Nuevo Arcoíris, 2010).

11 Las guerrillas liberales fueron organizaciones de personas del partido liberal que se alzaron en armas como una forma de resistencia frente a los atropellos que cometía el gobierno conservador. Actuaron principalmente en los departamentos de Casanare y Boyacá, Tolima, caldas, Antioquia, los Santanderes y Cauca, grupos que llegaron a tener niveles importantes de articulación que los presentaba como un levantamiento popular. En este orden se constituyeron en grupos de autodefensas frente a la pretensión conservadora de volverse hegemónica en el manejo y control del estado, mientras los conservadores los veían como la penetración en Colombia de ideas disociadoras como las ideas marxistas. Sobre guerrillas liberales ver: Eduardo Franco Isaza. Las guerrillas del Llano (Colombia: Hombre Nuevo, s.f.); Justo Aguilar Casas, La violencia en los Llanos Orientales. "Comando de los hermanos Bautista" (Bogotá: Ecoe Ediciones, 1986). Reinaldo Barbosa Estepa, Guadalupe y sus centauros, (Bogotá: Universidad Nacional, CEREC, IEPRI, 1992); Eduardo Fonseca Galán, Los Combatientes del Llano 1949-1953. (Bogotá: Impresión universidad INCA de Colombia, Unidad editorial, 1987); entre otros.

12 Pereyra, Del Moncada..., 6-62.

13 Pereyra, Del Moncada..., 62. 
favorable a las fuerzas guerrilleras ${ }^{14}$. Casi en el mismo orden se encuentra el planteamiento de Elsa Blair hablando de más o menos unos 20.000 hombres alzados en armas, con niveles de articulación como lo demuestra la Conferencia de Boyacá en 1952 organizada por los comunistas, y la promulgación de La Primera Ley del Llano en el mismo año por parte de las guerrillas liberales ${ }^{15}$. Estos desarrollos son leídos por estos autores como el comienzo en la transformación de la lucha partidaria en una lucha social. Se trató de una coyuntura en donde algunos de los grupos armados catalogados como guerrillas luchaban contra el gobierno y no contra el sistema, mientras otros, que ya tenían una mayor educación política e ideológica como las guerrillas del Sumapaz y del Tolima, definían sus objetivos contra el sistema, según Gonzalo Bermúdez ${ }^{16}$. A pesar de ser precaria la formación y estructuración de estos grupos, algunos habían entrado en una fase de transición hacia la construcción de verdaderas guerrillas, aunque sólo fuera, como afirma este mismo autor, la primera fase de la lucha clasista ${ }^{17}$.

Como complemento de esta coyuntura se encuentran las presiones que diferentes actores, incluido los Estados Unidos, ejercían sobre el partido liberal para que definiera sus relaciones con el comunismo representado en el partido comunista y el sindicalismo. Dentro de este juego de presiones tuvo lugar la prohibición del comunismo a través del Acto legislativo $\mathrm{n}^{\circ} 6$ de 1954 emitido por la Asamblea Nacional Constituyente el 7 de septiembre ${ }^{18}$. El Artículo $1^{\circ}$ reza: «Queda prohibida la actividad política del comunismo internacional. La ley reglamentará la manera de hacer efectiva esta prohibición» ${ }^{19}$. Y efectivamente, el Decreto Legislativo 434 de

14 Gonzalo Bermúdez Rossi. El poder militar en Colombia. De la colonia al Frente Nacional. (Bogotá: Ediciones Expresión, 1982), 69.

15 Elsa Blair Trujillo. Las Fuerzas Armadas. Una mirada civil. (Colombia: Cinep, 1993). 66.

16 Bermúdez Rossi, El poder militar..., 97.

17 Bermúdez Rossi, El poder militar..., 79.

18 El Acto Legislativo fue firmado por el Presidente Gustavo Rojas Pinilla y por el Ministro de Gobierno Lucio Pabón el 14 de septiembre de 1954.

19 Diario Oficial n 28607, Bogotá, 21 de octubre de 1954. 
1956 reglamentó este mandato ordenando prisión de uno a cinco años o relegación a colonia penal agrícola para quien tomara parte en actividades políticas de índole comunista; interdicción del ejercicio de derechos y funciones públicas por diez años; y en incapacidad para actuar como dirigente sindical por el mismo tiempo ${ }^{20}$.

Adicionalmente, en este periodo se puso a prueba la experiencia adquirida por el Ejército en Corea junto con los aprendizajes en Estados Unidos, y se propició toda la modernización ideológica, organizacional, táctica y logística con la nueva dotación armamentística de las FFMM, incluida la unificación de las fuerzas en un solo mando, hecho que se produjo en 1952 con la creación del Comando General de las Fuerzas Armadas, adscrito hasta el entonces Ministerio de Guerra (hoy Ministerio de Defensa) ${ }^{21}$; con estas acciones, la aparente neutralidad política del Ejército se rompió e inició a ser actor importante de la vida política a través de sus más altos dirigentes que pasaron a ocupar cargos como Ministros, Gobernadores, Alcaldes y otros cargos de la administración pública $^{22}$. Ahora estaban dentro del conflicto al lado de las ideas anticomunistas del conservatismo y de sectores liberales, respondiendo a los objetivos de seguridad militar y haciendo el trabajo de contención del campo político del comunismo.

En términos generales se puede afirmar que esta fue una fase donde las políticas y los lenguajes orientados desde los Estados Unidos se adoptaron sin discusión alguna, salvo unas tibias controversias frente a la actividad religiosa de los protestantes -que podían ser semillas para el comunismo-, y algunas insinuaciones de divergencia frente a la función del capital internacional y su papel en la disminución de la pobreza y desigualdad, planteadas por Gustavo Rojas como

20 «Decreto 434 de 1 de marzo de 1956». Diario Oficial n² 28987, Bogotá, 14 de marzo de 1956, 755 .

21 Estudios sobre los cambios estructurales y operativos de las Fuerzas Armadas se pueden ver en: Blair, Las Fuerzas Armadas..., 72; Gustavo Gallón, La república de las Armas (Bogotá: Cinep, 1978), 32-36; Adolfo León Atehortúa Cruz, Partidos, Violencia y Ejército 1934-1957. (Bogotá: Universidad Militar Nueva Granada, 2010), 146.

22 Ver: Gallón, La República de..., 26; Atehortúa Cruz, Partidos, Violencia..., 97-99. 
presidente. Instituciones y población estaban listas para el nuevo nivel de confrontación.

\section{Segunda Fase: Aparece con claridad el enemigo: 1958-1979}

En el contexto internacional este periodo estuvo limitado por las dos revoluciones insurgentes exitosas en América: la revolución cubana y la revolución nicaragüense. Igualmente coincide con la fase de existencia de varios modelos de movimientos comunistas a nivel internacional. Como afirma Hobsbawm:

Sólo a partir de 1956 tuvieron los revolucionarios la posibilidad de elegir entre varios movimientos eficaces desde el punto de vista político o insurreccional. Pero todos ellos -diversas ramas del trotskismo, el maoísmo y grupos inspirados por la revolución cubana de 1959- eran de inspiración más o menos leninista ${ }^{23}$.

De lo que derivó el fraccionamiento del movimiento comunista.

De otra parte, la llegada de Fidel Castro al poder y su posterior declaración de que en Cuba existía un régimen marxista-leninista se convirtió en el catalizador del miedo al comunismo, no sólo para los dirigentes norteamericanos, sino también para las clases adineradas de Latinoamérica como lo afirmó Tom Polgar que se desempeñaría como jefe del departamento de inteligencia exterior de los Estados Unidos, en la división latinoamericana, entre 1965 y $1967^{24}$. Frente a este hecho se inauguró lo que podría definirse como la fase de «acciones abiertas directas», primero con la llamada crisis de los misiles, luego, en 1965, con la intervención en República Dominicana ${ }^{25}$, continúo en 1973 con el derrocamiento en Chile del presidente Salvador Allende ${ }^{26}$. Para los norteamericanos

23 Eric Hobsbawm, Historia del siglo XX, (Buenos Aires: Crítica, 1994), 82.

24 Ver: Tim Weiner, Legado de Cenizas. La historia de la CIA (Barcelona: Debate,

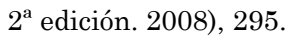

25 Ver: Weiner. Legado de..., 261.

26 Weiner. Legado de..., 322-328. 
fue la mejor manera de evitar que el comunismo internacional destruyera las democracias en Latinoamérica. Varios golpes de estado y apoyos a gobiernos dictatoriales ${ }^{27}$ en este periodo fueron justificados por la necesidad de establecer gobiernos fuertes que impidieran las amenazas del enemigo externo que actuaba a través del enemigo interno.

En este contexto internacional el triunfo de la revolución cubana cambió las dinámicas y las acciones de los Estados Unidos frente al resto del continente, y simultáneamente cambió el rol y la orientación de los organismos de cooperación. Con el derrocamiento de Batista en 1959, el comunismo dejó de ser un fantasma y se ubicó en las puertas del país más poderoso del mundo. Esta polarización se acentuó con las proclamaciones hechas tanto en la Primera como en la Segunda Declaración de la Habana, donde se planteó la necesidad de promover una liberación de América y del mundo frente a la fuerza más importante del sistema imperialista mundial, de ahí la decisión de los revolucionarios cubanos y del Che Guevara en particular, de impulsar la revolución armada en tierras suramericanas ${ }^{28}$ así como en Asia y África afirmando que "Atacar dura e interrumpidamente en cada punto de confrontación, debe ser la táctica general de los pueblos» ${ }^{29}$. A partir de esta coyuntura, la presencia de guerrillas en el resto del continente fue una realidad ${ }^{30}$ y una preocupación

$27 \quad$ Existe una larga lista de dictaduras y golpes de estado en América durante la Guerra Fría. Países como Brasil, Paraguay y Chile se caracterizaron por dictaduras de larga duración, mientras países como Argentina, Ecuador, Perú, Honduras, El salvador, República Dominicana, entre otros, combinaron dictaduras con gobiernos civiles. Ver: "Dictaduras militares en américa latina», Historia Internacional, acceso el día 12 de marzo de 2017, https://es.slideshare.net/ELENAMELENDEZT/ dictaduras-militares-en-america-latina; «Dictaduras en América Latina. Doctrina de la seguridad nacional. Golpe de estado en Argentina», Historia Internacional, acceso el 12 de marzo de 2017, http://historiainternacionallocucion.blogspot.com.co/2010/09/ dictaduras-en-america-latina-doctrina.html

28 La segunda declaración de la Habana. 4 de febrero de 1962. (Canadá: pathfinder, Sexta impresión, 2006).

29 Ernesto Che Guevara, «Crear dos, tres... muchos Viet Nam, es la consigna», en Rebelión Tricontinental, ed. Ulises Estrada y Luis Suárez (Cuba: Ocean Sur, 2006), 27.

30 Palabra Obrera, el Ejército Guerrillero del Pueblo (1963-1964), las Fuerzas Armadas Revolucionarias (FARC 1966-1973), el Frente Argentino de Liberación (FAL 1967-1969), las Fuerzas Armadas de Liberación (FAL 1969-1973), las Fuerzas 
adicional para la seguridad norteamericana. A esa presencia se le suman los intentos de coordinación global de las guerras tanto de liberación como las de orientación revolucionaria hacia el socialismo con la creación en la Habana Cuba, el 15 de enero de 1966, de la Organización de Solidaridad de los Pueblos de Asia, África y América Latina (OSPAAAL) bajo la secretaria de Osmany Cienfuegos Gorriarán ${ }^{31}$, así como la adopción de la consigna "Crear dos, tres, muchos Viet Nam» dejada en el documento Mensaje a todos los pueblos del mundo a través de la Tricontinental, ${ }^{32}$ por el Che antes de partir para Bolivia a crear el destacamento guerrillero internacionalista, consigna que se convirtió en una convocatoria a la solidaridad de muchos pueblos y sectores sociales. Bajo el lema de que el imperialismo era uno sólo y que debía atacársele por todas partes en una "guerra total» muchos grupos guerrilleros aparecen en los tres continentes, en algunos lugares con la pretensión de alcanzar el poder y en otros como una forma de respaldar las luchas del pueblo de Viet Nam, visto en ese momento como una nueva esperanza de victoria de todo el mundo.

La estrategia propuesta por el Che se puede sintetizar en el siguiente fragmento:

Hay que llevar la guerra hasta donde el enemigo la lleve: a su casa, a sus lugares de diversión; hacerla total. Hay que impedirle tener un minuto de tranquilidad, un minuto de

\footnotetext{
Armadas Peronistas (1968-1973), el Ejército revolucionario del Pueblo (ERP 1968 1976), los Descamisados (1968-1972), los Montoneros (1968-1979) son algunos de los grupos insurgentes que se forman en Argentina en ese periodo. En Paraguay aparecieron grupos como el Frente Unido de Liberación nacional (1959-1964); en Uruguay el Movimiento de Liberación Nacional -Tupamaros (1962-1973), las Fuerzas Armadas Revolucionarias Orientales (FARO 1970-1973), la Fuerza revolucionaria de los Trabajadores, entre otros. En Perú sobresale el Frente de Izquierda Revolucionaria, el grupo de Juaja, el Ejército de Liberación Nacional, al Guerrilla de Ayacucho, el Movimiento de Izquierda Revolucionaria (1962-1965), el Tupac Amarú. En Venezuela se destacó el Ejército de Liberación Nacional (ELN 1962), las Fuerzas Armadas de Liberación Nacional (FALN 1963-1970), el Movimiento de Izquierda Revolucionaria. “. guerra.Violencia ssi,1973), LUna visión completa de todas las guerrillas tanto de Sur América como de Centro América las presenta Daniel Pereyra en Del Moncada a Chiapas...

31 Ulises Estrada, prólogo al libro Rebelión Tricontinental, ed. Ulises Estrada y Luis Suárez (Cuba: Ocean Sur, 2006), 1.

32 Guevara. «Crear dos...», 233-37.
} 
sosiego fuera de sus cuarteles, y aún dentro de los mismos: atacarlo donde quiera que se encuentre; hacerlo sentir una fiera acosada por cada lugar que transite. Se hará más bestial todavía, pero se notarán los signos del decaimiento que asoma ${ }^{33}$.

Con este panorama, las acciones no podían seguir siendo de contención del comunismo. Si ya los Estados Unidos habían lanzado la consigna de no permitir otra Cuba, con ese nuevo ambiente revolucionario en los tres continentes, la respuesta no podía ser otra que intervenir en cualquier lugar donde el orden establecido fuese alterado poniendo en peligro sus intereses. Ahora se debía atacar y eliminar de raíz al comunismo donde quiera que mostrara sus tentáculos, para lo cual desarrollaron dos estrategias básicas: una orientada a disminuir las condiciones de pobreza de la población por medio del programa Alianza para el Progreso, buscando, a través de la cooperación económica, eliminar las grandes injusticias sociales, lo que no era nada distinto a intensificar el objeto mismo de la OEA de que «los países más prósperos o desarrollados pudieran contribuir con sus recursos al desarrollo de los atrasados» ${ }^{34}$. Colombia jugó un papel importante en este proceso a través de la presidencia de Alberto Lleras primer mandatario del Frente Nacional (1958-1962), quien aseguró que en política internacional Colombia debería:

[...] promover el desarrollo económico y el bienestar social en un mundo atrasado, feudal en muchas de sus formas, ansioso de un mejoramiento radical y rápido, en crecimiento demográfico vertiginoso, y destinado a ser en pocos años el más grande centro de perturbación del Occidente ${ }^{35}$.

Dilema que vivían igualmente la mayoría de Estados en el continente. Se trató de una respuesta de occidente ante el

33 Guevara. "Crear dos...», 94.

34 Alberto Lleras Camargo, "Historia y alcance de la Organización de los Estados Americanos", en Reflexiones sobre la Historia, el Poder y la Vida Internacional. Tomo II, comp. Otto Morales Benitez. (Bogotá: Tercer Mundo Editores - Ediciones Uniandes. 1994), 257.

35 Alberto Lleras Camargo, «Realizaciones del Primer Gobierno del Frente Nacional», en Reflexiones sobre la Historia, el Poder y la Vida Internacional. Tomo II, comp. Otto Morales Benítez. (Bogotá: Tercer Mundo Editores - Ediciones Uniandes. 1994), 217-218. 
atractivo mundo comunista que mostraba acelerados procesos de crecimiento y desarrollo; mientras en América Latina las políticas de empresa privada, libertad económica y libre competencia -planteadas como respuesta a las demandas en la IX Conferencia de Bogotá por Marshall-, no daban los frutos esperados en materia de justicia social. Lleras expresó la urgencia de este cambio a través de una carta enviada en 1958 al presidente Kubitscheck de Brasil, en la que señala:

Pero está llegando el momento en que habrá que tomar decisiones rápidas para impedir que nuestros pueblos se desengañen y desorienten sobre su porvenir y piensen que a su seguridad, a su bienestar y a la justicia social se les podría hacer el holocausto de libertades que no siempre entienden ni beneficia por igual a todas las clases sociales. El subdesarrollo latinoamericano es ya una carga para el mundo occidental y puede convertirse en un grave peligro. Existe la posibilidad de impulsar el desenvolvimiento económico latinoamericano y de convertir el continente entero en una reserva de la libertad, haciendo el experimento decisivo de transformar las condiciones de países atrasados sin que ninguno de los principios políticos, morales y jurídicos de nuestra civilización tengan que sacrificarse a esa empresa ${ }^{36}$.

En este mismo sentido, $\mathrm{n}$ un mensaje al Congreso, Alberto Lleras afirmó:

[...] el gobierno colombiano tomó constantemente la iniciativa para promover un cambio en la política de cooperación económica interamericana. No entendió, en ningún momento, que pudiera hacerse separación ente los diversos aspectos de la circunstancia histórica en que está viviendo la América Latina. Nuestra política exterior partía de un hecho cierto: el nuevo teatro de la guerra fría entre dos concepciones antagónicas del destino de la humanidad era, obviamente, nuestro hemisferio ${ }^{37}$.

La otra estrategia de confrontación con los posibles focos subversivos -más directa y abierta-, se plasmó inicialmente en el Plan LASO u «Operaciones de Seguridad para América Latina», y luego se concretó en la Doctrina de la Seguridad

36 Lleras Camargo, «Realizaciones del Primer Gobierno...», 218.

37 Lleras Camargo, «Realizaciones del Primer Gobierno...», 219. 
Nacional o de "contraguerrilla», que como la describe Joseph Comblin, no se trató sólo de una acción militar, sino de una práctica que abarcaba indirectamente toda la política ${ }^{38}$. Esta involucró procesos de unificación de las Fuerzas Armadas y policiales, la asignación a éstas de la tarea del control interno, -el orden interno-, la creación de grupos contraguerrillas con participación centralizada del mando pero con unidades de despliegue rápido y participación de la aviación, la resignificación de la inteligencia militar ubicándola con el papel de ser la fuente de información; del uso de todas las formas posibles para contrarrestar el avance del comunismo, incluida la tortura, el bombardeo, etc. Fue la aplicación de la estrategia de «quitar el agua al pez» que había utilizado Gran Bretaña en Malasia, Francia en Vietnam y Argelia, y Norteamérica en Vietnam, según Pereyra ${ }^{39}$. Todas estas acciones estuvieron acompañadas o promovidas por las dictaduras militares que se impusieron en el continente americano, o por legislaciones especiales que limitaron todo tipo de libertades, mientras los norteamericanos trataban de mostrarse al mundo como los abanderados precisamente de la libertad y de la democracia.

Se trató de una fase de la Guerra Fría donde se priorizó más el orden que la justicia. Estados Unidos, si bien miró a América Latina por el caso de Cuba a finales de los años cincuenta, y de Chile a comienzos de los setenta, su ojo estuvo puesto en el conflicto de Vietnam y en fortalecer su economía de libre mercado, bajo el supuesto de que si la economía funcionaba bien se podían evitar las crisis sociales. El precepto que aparece es que se necesitaba de una absoluta libertad de comercio y de capitales para alcanzar el desarrollo social. En este periodo, más que en hacer realidad la libertad y la democracia, la preocupación se centró en impedir las protestas sociales, en limitar las posibilidades de que la sociedad se empoderara en el poder para propiciar cambios, pero también en crear las condiciones para la seguridad de la inversión norteamericana en aumento; por esta razón, para los Estados Unidos fue

38 Joseph Comblin, El poder militar en América Latina, (Salamanca: Editorial sígueme, 1978).

39 Pereyra. Del Moncada a..., 29. 
prioritario el contar con gobiernos aliados y fuertes por lo que promovió por todos los medios, incluidas las prácticas que se describen de la CIA, la imposición de dictaduras de derecha en casi todo el continente, al igual que en países de Asia, África y Medio Oriente. El cuento de la «amenaza del comunismo internacional» estaba siendo capitalizado para lograr aglutinar la dirigencia y hacer que se actuara solidariamente con acciones que tomaron el carácter de intervencionismo en la vida interna de los estados. Las dictaduras y los gobiernos de derecha se convirtieron en formas «benignas» de gobierno, según lo muestra el presidente Nixon ${ }^{40}$.

En términos generales se puede afirmar que a nivel internacional la respuesta militar de los Estados Unidos se enmarcó dentro de la estrategia de reacción flexible ${ }^{41}$, que consistió en proporcionar la ayuda económica y militar, así como el entrenamiento a los aliados, sin comprometer abiertamente las fuerzas norteamericanas, o con el comprometimiento de las fuerzas convencionales donde fuera indispensable; contexto que estuvo acompañado de una relajación en la percepción frente a la intencionalidad soviética, es decir, se asumió que los soviéticos no estaban interesados en hacer de América un polvorín hacia el comunismo.

En el orden interno esta fase está marcada por el desarrollo del Frente Nacional como expresión de unidad de las élites políticas, por la consolidación de la columna vertebral sobre la cual se va a sostener el Frente Nacional: partidos Fuerzas Militares, por la puesta en escena de las estrategias de guerra psicológica para ganar la mente de los civiles: las campañas «cívico-militares», diseñadas por el Pentágono en 1962 dentro del Plan Laso (Latín American Security Operation), donde el ejército asumió la tarea de desarrollo de vías de penetración, campañas de salud y de educación

40 Weiner, Legado de Cenizas..., 383. Hace referencia a que en abril de 1971 el presidente Nixon comentó al gobierno del Sha de Irán: «Sólo quisiera que hubiese más líderes en el mundo con su capacidad de previsión. Y con su capacidad para gobernar, afrontémoslo, una dictadura virtual de una forma benigna».

41 Ver Lilia Bermúdez. Guerra de Baja Intensidad: Reagan contra Centroamérica. (México: Siglo XXI, $2^{\text {a }}$ edición. 1989), 21. 
orientadas a controlar a la población civil ${ }^{42}$. Para sacar adelante esa actividad las Fuerzas Militares se convirtieron en intermediarias entre los Ministerios de Obras Públicas, Salud y Educación, y la comunidad. Este radio de actividades se amplió en 1962 al asignarles la tarea de contribuir en la aplicación de la reforma agraria -influyendo así dentro del INCORA (Instituto Colombiano de Reforma Agraria)-.

Ahora bien, mientras en la primera fase las guerrillas se confundían entre guerrillas liberales, comunistas y en algunos casos guerrillas mixtas, algunas de las cuales se convirtieron en los antecedentes del bandolerismo de los años 50 y comienzos de los 60, y otras se sometieron a los procesos de paz impulsados por el gobierno de Rojas Pinilla en 1953, o simplemente deciden no operar más, para mediados de los años 60 están apareciendo las organizaciones armadas activas que asumen el carácter de guerrillas propiamente comunistas que enfrentan abiertamente al sistema, y que Alberto Lleras describe: «no es ya sólo un caso de bandidaje suelto sino que constituye un propósito internacional contra el sistema político prevaleciente en el hemisferio» ${ }^{43}$.

Así, la creación de las guerrillas comunistas de las FARC, el ELN y el EPL estuvo relacionada con el contexto internacional, con la respuesta a la aplicación de las políticas de Seguridad Nacional como el bombardeo a zonas donde los campesinos orientados por el ilegalizado partido comunista había concentrado su acción tales como Sumapaz, Yacopí y Viotá, Córdoba, el Tolima y el Huila principalmente, grupos que son debilitados por las mismas fuerzas del Estado desde su formación y que no representaron, en ese momento, una amenaza real a la seguridad y estabilidad del sistema político. Posteriormente, a mediados de la década de los años setenta,

42 Ver: «El Plan Lazo, o una derrota militar del PCC-FARC», Periodismo sin Fronteras, Acceso el 28 Julio de 2016, http://www.periodismosinfronteras.org/el-planlazo-o-una-derrota-militar-del-pcc-farc.html; Blair. Las Fuerzas..., 98-100; Bermúdez Rossi, El Poder Militar..., 126-130; Gallón, La República de las..., 24-25.

43 Morales Benítez, comp., Alberto Lleras Camargo..., 217. 
aparece el M-1944 con una propuesta urbana, con grandes hechos publicitarios y en un momento donde el sistema político centralista y clientelista estaba muy cuestionado, un momento de profunda crisis social que dio lugar a las protestas cívicas encontrando su cima con el paro de septiembre de $1977^{45}$. Este panorama constituyó para las élites gobernantes la manifestación abierta de que el comunismo estaba ad portas del poder.

El ascenso de la protesta popular y de la violencia guerrillera presentaba un ambiente en el que el enemigo interno, el comunismo, era visto con pasos gigantes. Este contexto llevó al Estado colombiano a hacer una readecuación de su operatividad a través del Decreto 1573 de $1974^{46}$, por medio del cual se crearon cinco frentes de trabajo, cada uno bajo la responsabilidad de un ministerio, todos en función de la Doctrina de Seguridad Nacional. Las tareas quedaron distribuidas así:

- Frente Interno: Ministerio de Gobierno

- Frente Externo: Ministerio de Relaciones Exteriores

- Frente Económico: Ministerio de Hacienda y Crédito Público

- Frente Militar: Ministerio de Defensa Nacional

- $\quad$ Frente Científico: Ministerio de Educación Nacional

El Frente Militar no sólo tuvo a su cargo la lucha antisubversiva sino que, como se planteó antes, copó acciones de otros ministerios, incluso asumiendo funciones de responsabilidad judicial frente a civiles y creó mecanismos de

44 Sobre el origen del M-19 ver: Paulo César León Palacios, «El espectacular lanzamiento de la guerrilla urbana en Colombia, el M-19 en 1974», Historias, Revista de la dirección de Estudios Históricos INAH, n 83, (2012): 103-111.

45 Ver: "Así fue el paro de 1977, el más grande (y violento) de la historia de Colombia», ¡Pacifista!, acceso el 25 de febrero de 2017, http://pacifista.co/asi-fue-elparo-de-1977-el-mas-grande-y-violento-de-la-historia-de-colombia/

46 El Decreto 1573 del 31 de julio de 1974 es el instrumento jurídico a través del cual se establecen los documentos que permiten estudiar y preparar las medidas y planes inherentes a la Seguridad Nacional y por medio del cual se da desarrollo a la Doctrina de la Seguridad Nacional en Colombia. Ver: Diario oficial, año cxi, n 34154 , 2 de septiembre de 1974, 10. 
vinculación directa con la población civil, incluyendo sectores de ésta dentro de lo que se llamó "militares de la reserva» que eran grupos de civiles -principalmente de industriales, comerciantes y agentes de la burocracia- que tenían la responsabilidad indirecta de ser agentes en las empresas para controlar los sectores de trabajadores y posibles actores del comunismo. Una especie de espías. Detrás de todas estas acciones estuvo la Doctrina de Seguridad Nacional, que como describe Gustavo Gallón, su credo,

[...] afirma la existencia de una guerra permanente entre el occidente cristiano y el oriente comunista cuya expresión en las naciones latinoamericanas ante la imposibilidad presente de enfrentamiento armado mundial se daría a través de la insurrección revolucionaria actual o potencial dentro de cada país ${ }^{47}$.

Esta nueva etapa de la lucha revolucionaria y la presencia de organizaciones políticas legales de izquierda disputando el poder al Frente Nacional, induce a las fuerzas armadas a reorientar su política hacia aspectos cada vez más sutiles de poder; no solo se trataba de enfrentar a estos grupos en el terreno puramente militar, sino que se orientó el trabajo hacia la guerra psicológica ${ }^{48}$, «hacia las mentes y las conciencias de la población civil» ${ }^{49}$. La generalidad de las Fuerzas Militares ya habían hecho propio el credo anticomunista y adoptado las estrategias de guerra irregular para contrarrestar al enemigo.

47 Gallón Giraldo, «La República de las Armas...», (Bogotá: Cinep, 1978). 49.

48 «La guerra psicológica es el empleo planeado en tiempo y espacio de operaciones globales en las zonas de guerra; la propaganda y las cruentas acciones bélicas ejercen influencia en las opiniones, sentimientos, actitudes de los grupos revolucionarios, colaboradores o neutrales, a fin de que estos apoyen los objetivos perseguidos por el sistema; destruyen en los primeros su unidad espiritual, les crean dudas, temores e incertidumbres, que desarticulan los elementos de su personalidad; de los colaboradores o amigos de la represión, aseguran en mejor forma su empleo». Tomado de «Operaciones psicológicas», Escuela de Infantería 065-808, Bogotá, 1965. Citado por Bermúdez Rossi, El Poder Militar..., 130. Este mismo autor dice que la «Guerra Psicológica" no es otra cosa que la violencia organizada pero en especial encauzada contra la mente humana, que es el objetivo hacia el cual se dirigen todos los ataques». (p. 133).

49 Bermúdez Rossi, El poder Militar..., 125. 
Es igualmente una fase donde Colombia fue objeto de una de las mayores intervenciones económicas del continente ${ }^{50}$, en alguna medida como contraprestación a la fidelidad mostrada por este país hacia las políticas anticomunistas orientadas por los Estados Unidos. Al respecto, el Embajador Cabot decía: «Si queremos que Colombia emprenda otros programas militares [...] en nuestro interés [...], tendremos que pagar por ellos, por lo menos como una forma de proteger a Colombia de las cargas económicas que la agobian en este momento [...] $\aleph^{51}$.

De otra parte, como efecto abierto de la Guerra Fría, luego de las experiencias obtenidas por nuestro ejército con las escuelas de lanceros o Escuelas Rangers de los Estados Unidos, en donde participan nuestros militares a partir de 1955 en cursos que se reproducirían en Colombia a partir de diciembre de 1955 con la organización de la Escuela en El Nilo (Cundinamarca), Colombia se convirtió en escuela de formación en tácticas de contraguerrilla para diferentes ejércitos de América Latina. La importancia de este tipo de preparación radicó en que el curos fue considerado como «el más indicado para la adquisición de la técnica de combate irregular, toda vez que se les capacitaría como comandantes de pequeñas unidades para el cumplimiento de misiones especiales» ${ }^{52}$. Se trató de preparar al ejército en la conducción de pequeñas patrullas de infantería, que en adelante se convirtió en estrategia antisubversiva.

Con esta nueva orientación y con los desarrollos que estaba teniendo la insurgencia en el continente, la "guerra de guerrillas» sería en adelante la estrategia que se tendría que afrontar, así lo reconoce el ejército en 1962. La experiencia que va adquiriendo el ejército colombiano y que se extiende a las demás fuerzas armadas, incluida la policía, llevaron a

50 «El Export-Import Bank continuó asignando fondos para la liquidación de las deudas comerciales, así como para construcción de carreteras, desarrollo agrícola, mejoras en los sistemas de transporte, desarrollo hidroeléctrico, instalaciones portuarias y construcción de hoteles». Ver: Stephen J Randall, Aliados y distantes. (Colombia: Tercer Mundo Editores y ediciones Uniandes, 1992), 244.

51 Citado por Randall, Aliados y..., 244.

52 Ver: Atehortúa Cruz, Partidos, Violencia..., 202 
hacer de las fuerzas militares una escuela de formación en la lucha contra las guerrillas y contra el comunismo. Al respecto Adolfo Atehortúa sostiene que:

\begin{abstract}
Como resultado de la promovida necesidad y efectividad de los lanceros, las fuerzas militares de varios países latinoamericanos solicitaron asistir a los cursos contraguerrilleros dictados en Colombia, los cuales empezaron a programarse en 1966 como versión internacional, con el aval de la Escuela de las Américas ${ }^{53}$.
\end{abstract}

Así, dentro de ese marco de la Doctrina de la Seguridad Nacional se puso todo el aparato político del Estado a funcionar bajo la lógica de la Guerra Fría: ahora no sólo era la contención, había que prevenir el comunismo actuando directamente sobre las condiciones sociales y económicas de las comunidades. Contradictoriamente, mientras en el orden internacional se hablaba de distención entre las potencias en la medida que el mundo fue rompiendo el bipolarismo para dar paso a un multipolarismo, con la aparición de China en el campo comunista y de la Unión Económica Europea, primero y luego Unión Europea en la órbita capitalista y por la existencia de un respeto tácito entre Estados Unidos y la Unión Soviética, iniciado por Jimmy Carter ${ }^{54}$ en el orden interno las fuerzas que se estaban consolidando como antagónicas entran en un proceso de radicalización que elevó las tensiones y las preocupaciones: De un lado, el Partido Comunista adoptó en 1961 la bandera de la "combinación de todas las formas de lucha» asumiendo con esta una actitud abiertamente favorable a la acción armada, coincidiendo con otras organizaciones políticas como el Movimiento Obrero Estudiantil Campesino (MOEC) y el Frente Unido de Acción Revolucionaria (FUAR), dirigido por el sacerdote Camilo Torres, y en la línea dura y las juventudes del MRL proclives a la retórica revolucionaria ${ }^{55}$. De otro lado, los partidos tradicionales, a través de las políticas del Frente Nacional, también se ubicaron del lado promotor

\footnotetext{
53 Atehortúa Cruz, Partidos, Violencia..., 203.

54 Powaski, La guerra..., 251-253.

55 Ver: Jorge Child, «El MRL», en Entre movimientos y caudillos: 50 años de bipartidismo izquierda y alternativas populares en Colombia, comp. Gustavo Gallón (Bogotá: Cinep, 1989) 76-77.
} 
de las acciones de choque, de tal forma que mientras el mundo estaba hablando de distensión, nosotros estábamos en plena tensión de las fuerzas contradictorias.

Se podría sintetizar esta fase afirmando que fue un momento en el cual la política norteamericana comprendió dos campos claramente definidos con un mismo fin: de un lado estaban las acciones encaminadas a disminuir las condiciones de miseria y pobreza con programas como la Alianza para el Progreso y el proyecto de reforma agraria; de otro lado estaban las políticas y las acciones encaminadas a impedir el avance de las fuerzas revolucionarias para lo cual los Estados Unidos mostraron su disponibilidad de apoyar incondicionalmente cualquier tipo de régimen represivo, con tal de que actuara en contra de todo lo que tuviese aire revolucionario. Los ideales de libertad y democracia que habían orientado, el discurso durante la primera fase fueron reemplazados por la aplicación de la seguridad a cualquier precio. Era la antesala del relanzamiento de la Guerra Fría con el auge de las guerrillas centroamericanas y suramericanas.

\section{Tercera Fase: La amenaza se hace real: 1979-1991}

Esta fase final de la Guerra Fría, fue, tal vez, la fase más violenta para el continente. Tiene como límite inferior -en el contexto internacional- el triunfo de la guerrilla nicaragüense que logra derrocar del poder a Fulgencio Somoza, como límite superior el derrumbe de la Unión Soviética; y en Colombia inicia con la expedición del estatuto de la seguridad nacional (Decreto 1923 de 1978), y finaliza con la expedición de una nueva carta política en la que juegan un papel importante grupos guerrilleros como: el M-19, el EPL, el MAQL, el PRT, grupos guerrilleros desmovilizados que reclaman su participación en la Asamblea Nacional Constituyente. Fue un periodo en el que la amenaza de la subversión como actor con capacidad para acceder al poder se hizo real en forma particular en Centroamérica ${ }^{56}$. De un lado, los núcleos guerrilleros

56 Ver: «Nicaragua: insurrección general: la única salida», Alternativa $\mathrm{n}^{\circ}$ 199, Bogotá, 12 a 19 de febrero de 1979, 37. «Caribe, Huracán Político», Alternativa n 231, Bogotá, 20 a 27 de septiembre de 1979, 26-27; Carlos Agudelo C, «El Salvador, 
unificaron sus fuerzas en países como Perú, Guatemala, El Salvador, Nicaragua, y en el caso colombiano hubo intentos con la propuesta de creación de la Coordinadora Guerrillera Simón Bolívar. En algunos de estos espacios las guerrillas se transformaron en organizaciones político-militares ${ }^{57}$, lo que les permitió movilizar grandes sectores de la población a favor de la revolución y en contra de los gobiernos promovidos por los Estados Unidos ${ }^{58}$. Simultáneamente se puso en práctica toda la política contrainsurgente orientada desde el país del norte que comprendió todo tipo de acciones con el fin de reducir la influencia subversiva, acciones dentro de las que se incluyó el asesinato selectivo de líderes, la guerra sucia, limpieza de zonas de presencia subversiva para luego atacar sus bases, el bombardeo masivo de sectores populares, todo esto con la asesoría de militares norteamericanos como quedó demostrado con el asesinato de un consejero militar en El Salvador ${ }^{59}$ y con los contras en Nicaragua ${ }^{60}$.

En esta dirección estuvo igualmente la acción de los gobiernos norteamericanos de promover procesos de diálogo con las guerrillas centroamericanas y con las de Colombia; pero ante el fracaso de éstas, se impuso como eje de la política internacional el terrorismo internacional, promovido por el gobierno de Reagan en reemplazo de la bandera de los derechos humanos que había estado detrás de la política intervencionista de los gobiernos de Ford y de Carter. El triunfo

una tregua tensa", Alternativa ${ }^{\circ}$ 240, Bogotá, 22 a 29 de noviembre de 1979, 24-27. Alexander Leskin, Washington contra Nicaragua (Moscú: Agencia de prensa Novosti, 1986).

57 Ver: «Nicaragua, Insurrección general: la única salida», Alternativa $\mathrm{n}^{\circ} 173$, Bogotá, 12 a 19 de febrero de 1979, 37.

58 Para el caso de El Salvador ver: Mario Menendez, El Salvador: guerra civil y revolución, proceso y protagonistas. (Colombia: La Oveja Negra, s.f).

59 El comandante de marina Albert Schaufelberger, fue asesinado el 25 de mayo de 1983 por parte del Frente Farabundo Martí para la Liberación Nacional (FMLN). El militar formaba parte de un grupo de 55 militares responsables de entrenar a militares de la región en la lucha contra la guerrilla. Ver «Incertidumbre sobre las repercusiones del asesinato en la futura política de EEUU en Centroamérica», El País, acceso el 25 marzo 2017, http://elpais.com/diario/1983/05/27/internacional/422834401_850215. html

60 Ver: «La embarrada de Reagan», Semana n²39, Bogotá, 8 de diciembre de $1986,52-61$. 
de las guerrillas sandinistas en Nicaragua abrió otro boquete para el comunismo en el continente; por lo que el gobierno norteamericano no estaba dispuestos a permitirlo, según dijo el director de la CIA del gobierno Reagan, Bill Casey, que las acciones contra el comunismo en Centroamérica eran "acciones de poca monta" que debía ser transformado en un enorme y extenso programa paramilitar, coordinado por él mismo. Por esta razón Casey no sólo buscó echar a los sandinistas del poder e impedir que las armas nicaragüenses salieran de allí para alimentar a las otras guerrillas del continente, sino que se propuso proporcionar más armas a los caudillos militares en el poder ${ }^{61}$. Según Tim Weiner:

Muchas de las operaciones de la CIA fueron concebidas por Casey como grandes diseños destinados a reforzar a un aliado de Estados Unidos o a desangrar a un enemigo suyo, pero al final se redujeron a proporcionar armas a determinados caudillos militares ${ }^{62}$.

La promoción de los Contras, los escuadrones de la muerte y el paramilitarismo se volvieron común denominador en Centroamérica, Perú y Colombia, todo inscrito dentro de la confrontación Este-Oeste sin considerar los problemas internos, como afirmó Reagan frente a evitar una "Centroamérica

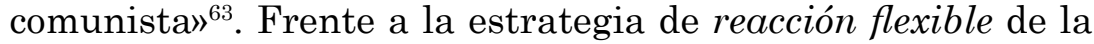
fase anterior, se impuso la de contrainsurgencia sustentada en la existencia de una nueva amenaza comunista como un ente monolítico que desafiaba el poderío del campo occidental $^{64}$. De las ayudas económicas y militares como centro del intervencionismo se dio paso a un intervencionismo directo con acciones abiertas de las fuerzas militares norteamericanas, con la formación de Contras que actuaron a través de la promoción del terror. Se trató de una coyuntura

\footnotetext{
61 Weiner, Legado de..., 398-399.

62 Weiner, Legado de..., 399.

63 «Discurso televisivo de Ronald Reagan sobre Centroamérica el 9 de mayo de 1984», citado por Mónica Toussaint, «Tomándole la temperatura a la Guerra Fría: episodios de la historia diplomática de México en Centroamérica», en Los diplomáticos mexicanos y la Guerra Fría. Memoria e Historia, 1974-1989, coord. Leticia Bobadilla González (México: Secretaría de Relaciones Exteriores - UMSNH, 2009), 128.
}

64 Bermúdez, Guerra de Baja..., 21. 
de radicalización tanto de las izquierdas que, ante los avances de las fuerzas revolucionarias, vieron factible la conquista del poder, como de los defensores del sistema encabezados por los Estados Unidos que quisieron a toda costa impedir el avance de la insurgencia y acudieron a aplicar el principio chino de quitarle el agua al pez; lo que significó, de un lado, atacar a la población civil -principalmente campesina-para eliminar cualquier posibilidad de respaldo a las luchas populares y, de otra parte, realizar acciones acompañadas de asesinatos selectivos en las ciudades, asesinatos que tenían la intensión de ser ejemplarizantes y propiciar el terror psicológico.

La "seguridad hemisférica», amenazada con los avances insurreccionales y los fracasos de los procesos de paz, hicieron de América Latina un objetivo de primer orden para los americanos. Había que actuar para detener el comunismo, ahora visto como una real amenaza para la especie humana. Para contrarrestarla, el Pentágono promovió las «guerras de baja intensidad» en donde el narcotráfico entró a jugar un papel importante como financiador de la misma. Con el beneplácito del Departamento de Estado y con la orientación de la CIA se establecieron alianzas entre Narcos y Contras o grupos Paramilitares. El caso más sonado fue el «escándalo Irán-Contras» que dejó al descubierto esta modalidad de política norteamericana. De esta forma, en los años ochenta, la guerra contrainsurgente fue delegada a actores privados, afirma Javier Guerrero ${ }^{65}$, teniendo como ejemplos de esto a los grupos AAA (Alianza Anticomunista Americana) en Argentina, el MAC (Movimiento Anticomunista Colombiano) y el MAS (Muerte A Secuestradores) en Colombia. Fue la guerra contrainsurgente por delegación pero con el auspicio y la orientación de los Estados Unidos.

Colombia siguió igualmente inmersa en esta lógica de la Guerra Fría, y sin necesidad de dictaduras militares pero sí con dictaduras civiles, vio cómo la confrontación fue abarcando

65 Javier Guerrero, «La sobre-politización del narcotráfico en Colombia en los años ochenta y su interferencia en los procesos de paz», en De las Armas a la Política, comp. Ricardo Peñaranda y Javier Guerrero (Bogotá: Tercer Mundo Editores - IEPRI, 1999), 245 . 
cada día más espacios que limitaron las libertades y las posibilidades de desarrollo democrático. La militarización de amplias zonas del país fue parte de la respuesta oficial ante el creciente clima conflictivo. El desarrollo de paros cívicos en los años setenta y el crecimiento de las fuerzas insurgentes, en particular con las acciones del M-19 como el robo de las armas del Cantón Norte en Bogotá, la toma de la Embajada de la República Dominicana a finales de los años setenta, que según Gustavo Gallón:

\section{[...] se contabilizaban como militarizadas permanentemente más de una tercera parte del territorio habitado del pais, que abarcaba especialmente a las regiones del Magdalena medio (ubicado en parte de los departamentos de Santander, Bolivar, Magdalena, norte de Antioquia y Cesar). Tequendama y Sumapaz, del centro hacia el norte de Colombia, la región de Urabá y los departamentos de Sucre, Córdoba y Guajira, al norte del mapa; y el departamento del Cauca y, más recientemente, los de Tolima, Huila y Caquetá, hacia el sur del pais ${ }^{66}$. (Cursiva original).}

Esta es sólo una descripción de la respuesta oficial ante los desarrollos del conflicto en el país. Al igual que en Centroamérica, en Colombia las guerrillas y las movilizaciones sociales estaban en crecimiento, hasta el punto de que la dirigencia política vio realmente amenazada su estabilidad $\mathrm{y}$, por ende se agudizaron también las acciones represivas por parte del Estado. Ejemplo de lo anterior es la puesta en marcha del Estatuto de Seguridad Nacional, impuesto por el entonces presidente Julio Cesar Turbay y toda la política contrainsurgente que se derivó de ésta. Ya no sólo se trataba de contener la violencia en los campos, ésta había regresado a las ciudades donde los cinturones de miseria se convertían en un abono propicio para la nueva fase de la violencia guerrillera.

Simultáneamente a la expansión de la violencia se sumó un nuevo actor, el narcotráfico y su derivado: el paramilitarismo que va a iniciar acciones como aliado del Estado en la lucha contra el comunismo para "limpiar todo aquello que se asociara a revuelta y protesta» en las regiones y localidades,

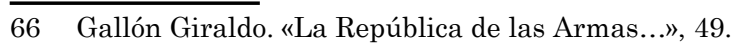


como asegura J. Guerrero ${ }^{67}$. Se trató de una alianza entre narcotráfico-paramilitarismo y Estado contra los avances revolucionarios y contra los procesos de paz que terminaron precisamente en el politicidio de la Unión Patriótica, el partido político con el que las FARC intentaron hacer política legal. Una alianza que tuvo sus raíces en la respuesta a las nuevas estrategias de financiación de la creciente guerrilla que incluyó el secuestro y la extorsión a finqueros y comerciantes, haciendo de estos sectores sociales unos potenciales aliados del gobierno para su lucha contra la subversión y en general contra todo lo que tuviese sabor a izquierda. Así, no sólo el establecimiento vio como enemigo a la oposición armada o desarmada, sino que ahora ésta también se convirtió en un peligro para los nuevos ricos derivados del narcotráfico, y en general para los sectores ligados a la actividad económica del país. Esto explica cómo en los años ochenta se facilitó la alianza narcotráfico-Estado, una situación que cambiaría en los años noventa donde el narcotráfico se ubicó por fuera de la institucionalidad, actuando en algunas regiones como aliado de la subversión y en otras como aliado del Estado. Así, el miedo al comunismo, es decir, la Guerra Fría de occidente, producía en los años ochenta una alianza de lo más perversa para la sociedad y estableció nuevos fines y objetivos para las políticas públicas.

Este nuevo panorama y entramado de la sociedad colombiana, en medio de la más aguda crisis institucional y de mezcla de todas las violencias, indujo nuevos procesos de paz en la administración de Virgilio Barco con participación del M-19, del EPL, del MAQL (Movimiento Armado Quintín Lame), del Partido Revolucionario de los Trabajadores PRT- que terminan como actores importantes en la Nueva Constitución de 1991, coincidiendo con la terminación de la Guerra Fría universal, el derrumbamiento del comunismo en Europa del Este y la desintegración de la Unión Soviética ${ }^{68}$.

\section{Conclusiones}

67 Guerrero, «La sobre-politización...», 222.

68 Powaski, La guerra..., 323. 
Se ha planteado una radiografía de las fases de la Guerra Fría en Colombia, que aunque tuvo elementos en común con la periodización que se ha hecho de la Guerra Fría universal, ésta tiene sus particularidades que muestran la necesidad de hacer seguimientos a las formas como se desarrolló en cada uno de los espacios de la geografía, proceso necesario para entender cómo cada país asumió o enfrentó políticas del contexto mundial, pero también para ver cómo ese contexto internacional transformó las realidades nacionales y sobre todo los imaginarios colectivos.

En buena medida se puede observar que la forma como se vivió en Colombia, y en general en el Continente americano el conflicto de la Guerra Fría, no responde a lo que se vivió en el concierto universal pues mientras, por ejemplo, en el orden universal durante los años sesenta se dio comienzo a un acercamiento entre los dos modelos que se habían declarado en 1947 como antagónicos e irreconciliables por el mismo presidente Truman, en América se presenta una intensificación de las contradicciones entre defensores del comunismo y los defensores del capitalismo que se manifiesta en la concreción de procesos subversivos con el auge de guerrillas en casi todo el continente, con la toma del poder por parte de organizaciones guerrilleras comunistas o por la llegada al poder de gobiernos de corte socialista, por un lado; pero de otra parte también con el endurecimiento y militarización de muchos regímenes incluidas las dictaduras que se convirtieron en la forma de gobierno mayoritario en el continente; mientras la tercera fase del concierto internacional corresponde a la disolución del comunismo, en el continente se intensifica la lucha contra el comunismo por el mismo avance de las organizaciones promotoras de esta forma de vida, con prácticas como el terrorismo de estado diseñado y promovido desde los Estados Unidos e implementado abiertamente por instituciones como la CIA. Lo anterior permite inferir la necesidad de construir análisis sobre realidades concretas que puedan dar pistas sobre la complejidad del fenómeno y la forma como en cada estado fueron asumidas políticas y prácticas que se tradujeron en algunos casos, como el colombiano, en afianzamiento de la crisis social y de la ola de violencia. 
Finalmente, es necesario para una mejor comprensión del pasado no perder de vista que la Guerra Fría fue en esencia una guerra por la conquista de las mentes, una guerra que se desarrolló a través de instrumentos de la guerra psicológica y que contó en Colombia con el apoyo de los líderes del gobierno que asumieron el control del Estado y el ejercicio del poder, lo que se traduce en que ésta hizo presencia en forma abierta o encubierta y que son esas raíces las que han influido en los procesos, las que hay que desentrañar para comprender mejor la historia nacional.

\section{Fuentes Documentales}

Agudelo C., Carlos. «El Salvador, una tregua tensa», Alternativa ${ }^{\circ}$ 240, Bogotá, 22 a 29 de noviembre de 1979.

«Caribe, Huracán Político», Alternativa n 231, Bogotá, 20 a 27 de septiembre de 1979.

«Decreto 434 de 1 de marzo de 1956». Diario Oficial n 28987, Bogotá, 14 de marzo de 1956.

Diario Oficial n 28607, Bogotá, 21 de octubre de 1954.

Diario oficial n 34154, Bogotá, 2 septiembre 1974.

Guevara, Ernesto Che. «Crear dos, tres... muchos Viet Nam, es la consigna». En Rebelión Tricontinental, editado por Ulises Estrada y Luis Suárez, 23-37. Cuba: Ocean Sur, 2006.

La segunda declaración de la Habana. 4 de febrero de 1962. Canadá: pathfinder, Sexta impresión, 2006.

«La embarrada de Reagan». Semana n² 239, Bogotá, 8 de diciembre de 1986.

"Nicaragua: insurrección general: la única salida», Alternativa $\mathrm{n}^{\circ}$ 199, Bogotá, 12 a 19 de febrero de 1979.

Weiner, Tim. Legado de Cenizas. La historia de la CIA. Barcelona: Debate, $2^{\mathrm{a}}$ edición. 2008. 


\section{Bibliografía}

Aguilar Casas, Justo. La violencia en los Llanos Orientales. "Comando de los hermanos Bautista». Bogotá: Ecoe Ediciones, 1986.

Aguilera Peña, Mario. Las FARC: la guerrilla campesina 19492010. ¿IIeas circulares de un mundo cambiante? Colombia: Corporación Nuevo Arcoiris, 2010.

Atehortúa Cruz, Adolfo León. Partidos, Violencia y Ejército. 19341957. Bogotá: Universidad Militar Nueva Granada, 2010.

Barbosa Estepa, Reinaldo. Guadalupe y sus centauros. Bogotá: Universidad Nacional, CEREC, IEPRI, 1992.

Bermúdez, Lilia. Guerra de Baja Intensidad: Reagan contra Centroamérica. México: Siglo XXI, 2ª edición, 1989.

Bermúdez Rossi, Gonzalo. El poder militar en Colombia. De la colonia al Frente Nacional. Bogotá: Ediciones Expresión, 1982.

Blair Trujillo, Elsa. Las Fuerzas Armadas. Una mirada civil. Colombia: Cinep, 1993.

Child, Jorge. «El MRL». En Entre movimientos y caudillos: 50 años de bipartidismo izquierda y alternativas populares en Colombia, compilado por Gustavo Gallón Giraldo, 68-90. Bogotá: Cinep, 1989.

Comblin, Joseph, El poder militar en América Latina, Salamanca: Editorial sígueme, 1978.

Estrada, Ulises., y Luis Suárez, ed. Rebelión Tricontinental. Cuba: Ocean Sur, 2006.

Fonseca Galán, Eduardo. Los Combatientes del Llano 1949-1953. Bogotá: Impresión universidad INCA de Colombia, 1987.

Fontaine, Andre. Historia de la Guerra Fría. Barcelona: Editorial Luis Caralt, 1970. 
Fontana, Josep. Por el bien del imperio. Barcelona: Pasado \& Presente, 2011.

Franco Isaza, Eduardo. Las guerrillas del Llano. Colombia: Hombre Nuevo, s.f.

Gallón Giraldo, Gustavo. La República de las Armas: Relación entre Fuerzas Armadas y Estado en Colombia 1960-1980. Bogotá: Cinep, 1978.

Gilhodés, Pierre. «El 9 de abril y su contexto internacional». En Grandes Potencias, el 9 de abril y la Violencia, editado por Gonzalo Sánchez, 45-62. Bogotá: Planeta, 2000.

Guerrero, Javier. «La sobre-politización del narcotráfico en Colombia en los años ochenta y su interferencia en los procesos de paz». En De las Armas a la Política, compilado por Ricardo Peñaranda y Javier Guerrero. Bogotá: Tercer Mundo Editores - IEPRI, 1999.

Hobsbawm, Eric. Historia del siglo XX. Buenos Aires: Crítica, 1994.

León Palacios, Paulo César. «El espectacular lanzamiento de la guerrilla urbana en Colombia, el M-19 en 1974». Historias, Revista de la dirección de Estudios Históricos INAH, n 83 (2012): 103-111.

Leskin, Alexander. Washington contra Nicaragua. Moscú: Agencia de prensa Novosti, 1986.

Lleras Camargo, Alberto. «Historia y alcance de la Organización de los Estados Americanos». En Alberto Lleras Camargo. Reflexiones sobre la Historia, el Poder y la Vida Internacional. Tomo II, compilado por Otto Morales Benítez. Bogotá: Tercer Mundo Editores - Ediciones Uniandes. 1994.

Lleras Camargo, Alberto. «Realizaciones del Primer Gobierno del Frente Nacional». En Alberto Lleras Camargo. Reflexiones sobre la Historia, el Poder y la Vida Internacional. Tomo II, compilado por Otto Morales Benítez. Bogotá: Tercer Mundo Editores - Ediciones Uniandes. 1994. 
Menéndez, Mario. El Salvador: guerra civil y revolución, proceso y protagonistas. Colombia: La Oveja Negra, s.f.

Pecaut, Daniel. Las FARC, ¿̇una guerrilla sin fin o sin fines? Bogotá: Norma, 2008.

Pereyra, Daniel. Del Moncada a Chiapas. España: Libros de la catarata, $2^{a}$ edición, 1995.

Powaski, Ronald. La Guerra fría. Estados Unidos y la Unión Soviética, 1917-1991. Barcelona: Crítica, 2000.

Randall, Stephen J. Aliados y distantes. Colombia: Tercer Mundo Editores y ediciones uniandes. 1992.

Sánchez, Gonzalo., ed. Grandes potencias, el 9 de abril y la violencia. Bogotá: Planeta, 2000.

Toussaint, Mónica. «Tomándole la temperatura a la Guerra Fría: episodios de la historia diplomática de México en Centroamérica». En Los diplomáticos mexicanos y la Guerra Fría. Memoria e Historia, 1974-1989, coordinado por Leticia Bobadilla González. México: Secretaría de Relaciones Exteriores - UMSNH, 2009.

Veiga, Francisco., y otros. La Paz simulada. Una historia de la Guerra Fría 1941-1991. Madrid: Alianza Editorial, 1997.

Villares, Ramón., y Ángel Bahamonde. El mundo contemporáneo. Siglos XIX y XX. Madrid: Taurus, 2001.

\section{Infografía}

El País. «Incertidumbre sobre las repercusiones del asesinato en la futura política de EEUU en Centroamérica». Acceso el 25 marzo 2017, http://elpais.com/diario/1983/05/27/ internacional/422834401_850215.html

Historia Internacional. "Dictaduras militares en américa latina». Acceso el día 12 de marzo de 2017, https://es.slideshare.net/ ELENAMELENDEZT/dictaduras-militares-en-americalatina 
Historia Internacional. «Dictaduras en América Latina. Doctrina de la seguridad nacional. Golpe de estado en Argentina». Acceso el 12 de marzo de 2017, http://historiainternacionallocucion. blogspot.com.co/2010/09/dictaduras-en-america-latinadoctrina.html

Historia1imagen. «Orígenes de la Guerra Fría. Winston Churchill "el telón de hierro", 5 de marzo 1946», Acceso el 13 de noviembre de 2013, https://historia1imagen.cl/2007/06/01/origenesde-la-guerra-fria-wiston-churchill-el-telon-de-hierro-5-demarzo-1946/

Otra clase de historia. «El punto cuatro del presidente Truman». Acceso el 27 de octubre de 2013, https://search.yahoo.com/yhs/ search?hspart=adk\&hsimp=yhs-adk_sbyhp\&p=el+punto+cua tro+del+presidente+truman\&param $1=20170308 \&$ param $2=2$ fb37d58-ffda-426c-ade9- 73c0501bf4f5\&param3=packages_5. $0.1 \sim \mathrm{CO} \sim$ appfocus5\&param $4=$ googledisplay $\sim$ Chrome $\sim$ el + pun to+cuatro+del+presidente+truman

¡Pacifista! «Así fue el paro de 1977, el más grande (y violento) de la historia de Colombia». Acceso el 25 de febrero de 2017, http:// pacifista.co/asi-fue-el-paro-de-1977-el-mas-grande-y-violentode-la-historia-de-colombia/

Periodismo sin Fronteras. "El Plan Lazo, o una derrota militar del PCC-FARC». Acceso el 28 julio de 2016, http://www. periodismosinfronteras.org/el-plan-lazo-o-una-derrotamilitar-del-pcc-farc.html

\section{Citar este artículo:}

González Cepeda, Liborio. «La guerra fría en Colombia. Una periodización necesaria». Historia Y MEMORIA, $\mathrm{n}^{\circ} 15$ (2017): 295-330. DOI: https://doi.org/10.19053/20275137. n15.2017.6119 